\title{
Completeness of follow up in a cohort study of mortality using the United Kingdom National Health Service Central Registers and records held by the Department of Social Security
}

\author{
S C Darby, J A O’Hagan, G M Kendall, R Doll, T P Fell, C R Muirhead
}

\begin{abstract}
Study objective-The aim was to evaluate and improve the completeness of follow up in a cohort study of mortality carried out using the UK National Health Service (NHS) Central Registers.

Setting-This was a follow up study of UK servicemen who served abroad in the 1950 s and 1960s, including those who participated in the UK atmospheric nuclear weapon tests and experimental programmes.

Design-Details of men for whom follow up achieved using the NHS Central Registers was unsatisfactory were submitted to the Department of Social Security (DSS) for tracing, as were details of men born before 1916 and reported by the NHS Central Registers as currently registered with a general practitioner, and a $1 \%$ sample of remaining men born in or after 1916.
\end{abstract}

Measurements and main results-The additional follow up increased the number of deaths fully identified in the cohort by $6.5 \%$. Mortality among those untraced on the NHS Central Registers was substantially greater than in the cohort as a whole $(10.2 \% \quad v \quad 6.9 \%)$. Among those reported by the NHS Central Registers as not currently registered with a general practitioner, $2 \cdot 7 \%$ were found to have died, as were $1.1 \%$ of men born before 1916 and currently reported to be registered with a general practitioner. As expected there was clear evidence that information about emigrations supplied by both the NHS Central Registers and DSS is far from complete.

Conclusions-Standardised mortality ratios based on follow up via the NHS Central Registers alone are likely to be somewhat low, and this should be borne in mind when interpreting the data.

The use of National Health Service (NHS) Central Registers to provide information about the vital status of individuals in cohorts under investigation is a standard procedure in epidemiological studies in the $U K,{ }^{1}$ so that knowledge of the extent of the completeness of follow up likely to be obtained is of considerable importance. We have recently reported the results of a study of mortality and cancer incidence in UK participants in the UK Atmospheric Nuclear Weapon Tests and Experimental Programmes ${ }^{2} 3$ in which information obtained from the NHS Central Registers was supplemented by information from the Department of Social Security (DSS) to ensure that follow up was as complete as possible. We report here the extent to which this additional information was obtained by the use of DSS records. The results presented include information about both deaths and emigrations, although it was recognised at the outset that emigrations would be greatly underreported by the NHS Central Registers. Nevertheless missing emigrations cause bias in epidemiological studies and we thought it would be helpful to have some estimate of its extent. Our study included $21531 \mathrm{UK}$ servicemen who were known to have visited any of five test locations in Australia or the Pacific Ocean during specified time periods between 1952 and 1967. An approximately equal number of servicemen who had not visited the test locations but who otherwise had similar characteristics were also included, so the total number of servicemen involved in the study was 43055 .

\section{Methods}

For each man in the study as many as possible of the following items were extracted from the Record of Service held by Ministry of Defence record custodians: surname, full forenames, previous names (if any), date and place of birth, nationality at birth, NHS number prior to enlistment in the Services, civilian address on enlistment together with its associated date, any subsequent civilian addresses together with their associated dates, and, if the Ministry of Defence had reason to believe that the man had died, the date and place of death. The details were then submitted to the NHS Central Register at Southport, which also took responsibility for tracing at its Edinburgh office where appropriate. For those individuals for whom there was a query from the NHS Central Register, or who were untraced on the NHS Central Registers, a check was made back to the Ministry of Defence Record of Service to see if all the available information had been correctly transcribed, and any corrections and additional information were forwarded to the NHS Central Registers. Where appropriate, attempts were made to trace men through the Health Departments in Northern Ireland, the Isle of Man, and Jersey, and the Health Departments in the Republic of Ireland and Guernsey were also requested to search for death certificates wherever it was likely that a man had died in one of these places. 
In order to improve the quality of the basic follow up, details of men in certain categories were submitted to the Records Branch of the DSS at Newcastle. The categories submitted were: (1) men recorded on the NHS Central Registers as not currently registered with a general practitioner; (2) men recorded either on the NHS Central Registers or on their Ministry of Defence Record of Service as dead but for whom no death details were available; and (3) men who remained untraced either on the NHS Central Registers or, where appropriate, on the Health Department records in Northern Ireland, the Isle of Man or Jersey. In addition, as a cross check, details of all men with date of birth prior to 1 January 1916 who had been reported as currently registered with an NHS general practitioner were submitted to DSS, as were details of a sample of approximately $1 \%$ of all remaining men born on or after 1 January 1916, selected by considering every 100th man on the database. The information forwarded to DSS comprised: surname and forenames, previous names (if any), National Insurance number, Service number, date of birth, and the reason for submitting the man's details.

The information available from DSS after their searches comprised whether or not the man had been successfully traced in their records and, for those who were traced, whether there was an indication that a death grant had been claimed for the man. For the purposes of the study, the information concerned was that relating to the individual's status on the date when our follow up was intended to cease ( 1 January 1984). If a claim had been made, the approximate date of death and the office where the claim had been lodged (usually a good indicator of place of death) were made available. For those men who had been untraced at the NHS Central Register and the Health Departments, DSS were asked to supply any extra available information such as town of residence, and they were usually able to supply this information when they could trace the man and found him to be living in the UK. DSS were also asked whether there was any evidence that the individual might have emigrated. However a shortage of skilled staff meant that this check could be carried out on only about three quarters of the 3462 men for whom details were submitted. Where the DSS searches reported a death previously unreported by the NHS Central Registers, or if DSS could provide any extra information that might assist in the tracing of a previously untraced individual, the information was referred back to the NHS Central Registers.

The previous reports of this study include, in addition to the UK servicemen described above, about 800 test participants who were civilian employees of the Atomic Weapons Establishment at Aldermaston and the Atomic Energy Research Establishment at Harwell, plus a similar number of civilian controls. These civilians have been excluded from the present report, because the method of follow up for these men was somewhat different from that for servicemen since information compiled for the Medical Research Council's study of Atomic Weapons Establishment employees was made directly available to the present study by the NHS Central
Register. ${ }^{4}$ In the present paper, we have also excluded from the numbers of individuals submitted to DSS those individuals for whom the initial response from the NHS Central Register caused us to submit details to the DSS but where the Central Register later (and independently) provided revised information on the basis of which these details would not have been sent to the DSS. In our other reports the information obtained from the NHS Central Registers was sometimes supplemented by information from Ministry of Defence sources; for example, for some men who were thought to have died, but for whom it was impossible to ascertain the cause of death from other sources, information was sought from the Ministry of Defence. Similarly men who were not satisfactorily traced on the NHS Central Registers were assumed to have emigrated if the Ministry of Defence had supplied an address outside the UK after the man's discharge from the services. For these reasons, the numbers reported here differ somewhat from those given in our previous reports. ${ }^{23}$

\section{Results}

Details of 43055 test participants and controls were submitted for tracing. The quality of the information submitted was high, in that the surname, at least one forename, and the date of birth were available for all 43055 . Place of birth was available for $42393\left(98.5^{\circ} \mathrm{o}\right)$; at least one civilian address was available for $42061\left(97 \cdot 7^{\circ}{ }_{0}\right)$; and NHS number was available for 31469 $(73.1 \%)$. The results of our initial investigations are given in table I. We found no indication of differing success in following up test participants as opposed to controls, and results for the two groups have therefore been combined. For 39542 men $(91.8 \%)$, the outcome of the tracing with the NHS Central Registers or Health Departments was apparently satisfactory, in that the man was either found to be currently registered with an NHS general practitioner, embarked, traced as alive in Northern Ireland, Isle of Man or Jersey, or else death details, including cause of death, were supplied by the NHS Central Registers or one of the Health Departments.

Of the 3513 men for whom the follow up was unsatisfactory (groups 5 to 8 in table I), 51 had been reported by the Ministry of Defence as still in service on 1 January 1984, and so no further action was taken to trace them. All 51 men were reported by NHS Central Register as not currently registered with a general practitioner. Details of the remaining $3462(8.0 \%)$ for whom the outcome of the initial tracing attempt was unsatisfactory were submitted to DSS, and the results are shown in table II.

Of the 123 men for whom some evidence of death but no cause was available before contacting DSS, 14 were reported by DSS as alive and living in the UK. For 11 of these 14 men the initial report of the death had come from the Ministry of Defence, although none were reported to have died in service. For four of these 11 the death was confirmed by the Office of Population Censuses and Surveys (OPCS), although for three of the four the death had occurred abroad and a certificate containing the cause of death was not 
available, and for the remaining one no further information was available. For a further six out of these 11 there was some evidence that the man had emigrated, in that the final address held by the Ministry of Defence after discharge was outside the UK. The last man was reported by the Ministry of Defence as having died in 1974. DSS, however, reported that he was alive and in the UK in 1981, and the NHS Central Register was unable to trace his death. It therefore seems likely that the initial report by the Ministry of Defence was incorrect. For the other three deaths the initial report of the death came from OPCS; one was said to have died abroad, but no information other than the date of death was available for the remaining two and we concluded that the reports of death were probably inaccurate.

For 101 of the men for whom some evidence of death but no cause was available before contacting DSS, the death was confirmed by DSS. Ninety three of these men had either died in service (52) or the initial report of death had come from the Ministry of Defence (41). Sixty four of the 93 were confirmed by OPCS and of these 26 were said to have occurred in England and Wales, two in Scotland, two in Northern Ireland, 33 abroad, and for one the place of death was unknown;

Table I Outcome of attempt to follow up 43055 UK servicemen with the National Health Service Central Registers (NHSCRs) at Southport and Edinburgh and the Health Departments in Northern Ireland, the Isle of Man, and Jersey. (Information obtained as a result of follow up at the Records Branch of the Department of Social Security, Newcastle, is excluded.

\begin{tabular}{|c|c|c|c|}
\hline \multicolumn{2}{|c|}{ Outcome of follow up attempt } & \multicolumn{2}{|c|}{$\begin{array}{l}\text { No of men } \\
\text { (percentage) }\end{array}$} \\
\hline 1 & $\begin{array}{l}\text { Registered with an NHS general practitioner in England, Scotland } \\
\text { or Wales }^{\mathrm{a}}\end{array}$ & 34234 & $(79 \cdot 5)$ \\
\hline 2 & $\begin{array}{l}\text { Traced alive with Health Departments in Northern Ireland, the } \\
\text { Isle of Man or Jersey }\end{array}$ & 370 & $(0 \cdot 9)$ \\
\hline 3 & Emigrated & 2206 & $(5 \cdot 1)$ \\
\hline 4 & $\begin{array}{l}\text { Deceased by January 1,1984, and registration details including } \\
\text { cause of death supplied by NHSCRs, or Health Departments in } \\
\text { Northern Ireland, the Isle of Man, Jersey, Guernsey or Dublin }\end{array}$ & 2732 & $(6 \cdot 3)$ \\
\hline 5 & $\begin{array}{l}\text { Deceased by January } 1,1984 \text {, but no cause of death available from } \\
\text { NHSCRs or other Health Departments }\end{array}$ & 123 & $(0 \cdot 3)$ \\
\hline 6 & $\begin{array}{l}\text { Traced on NHSCRs and not currently registered }{ }^{\mathrm{b}} \text { with a general } \\
\text { practitioner in England, Wales or Scotland and no indication of } \\
\text { residence in Northern Ireland, the Isle of Man or Jersey }\end{array}$ & 2693 & $(6 \cdot 3)$ \\
\hline 7 & $\begin{array}{l}\text { Untraced on NHSCRs and no indication of residence in Northern } \\
\text { Ireland, the Isle of Man or Jersey }\end{array}$ & 581 & $(1 \cdot 3)$ \\
\hline 8 & $\begin{array}{l}\text { Not in groups } 1-7 \text {, some evidence of residence in Northern } \\
\text { Ireland, the Isle of Man or Jersey, but untraced at the relevant } \\
\text { Health Department }\end{array}$ & 116 & $(0 \cdot 3)$ \\
\hline \multicolumn{2}{|c|}{ Total } & \multicolumn{2}{|c|}{$43055(100)$} \\
\hline
\end{tabular}

corresponding death certificates were eventually obtained for 23, 0,2, 10 and 0 men respectively. For all but one of the 17 deaths reported by the Ministry of Defence but not confirmed by OPCS there was some evidence that the man had died abroad and for only one of them was a certified cause eventually found. For the remaining eight deaths the initial report had come from NHS Central Registers, although a death certificate could not be found even with the extra information from DSS. Three of these eight deaths occurred abroad, one in Scotland, and for the remaining four (three reported by DSS as occurring in England and one in Northern Ireland), different dates of death were reported by the NHS Central Register and DSS, although both agreed that the man had died.

Three men for whom some evidence of death had been available before contacting DSS were reported by DSS to have emigrated. For all three, confirmation of their emigration was available in that for two the final address after discharge held by the Ministry of Defence was outside the United Kingdom, and for the remaining man OPCS confirmed that the death took place in Jakarta, although no cause was available.

The remaining five men for whom some evidence of death was available before contacting DSS were untraced at DSS. For all five the fact that the man had died had been reported by the Ministry of Defence, three were said to have died abroad (one of these was confirmed by OPCS), one (also confirmed by OPCS) with place unknown and the remaining man was said to have died in service in the UK.

Of the 2642 men who had been traced on the NHS Central Registers but who were not currently registered with a general practitioner, 2289 were reported by DSS as alive and living in the United Kingdom according to their records and a further one was reclassified by DSS as alive after a report of death could not be confirmed by OPCS, making a total of $2290\left(86 \cdot 7^{\circ}{ }^{\circ}\right.$ see table II). For a further 83 of the $2642\left(3 \cdot 1^{\circ}{ }_{0}\right)$, DSS reported that the man had died. For 72 out of these 83 , the additional information provided by DSS on date and place of death enabled OPCS to locate the death certificate (57 took place in England or Wales, 11 in Scotland, one in Northern Ireland, one in Eire, and two elsewhere overseas). For the remaining 11, OPCS were still unable to confirm the death even with the extra
Table II Numbers of men for whom follow up achieved using National Health Service Central Registers (NHSCRs) at Southport and Edinburgh and Health Departments in Northern Ireland, Isle of Man, and fersey was unsatisfactory, by outcome of initial attempt at follow up and outcome of cross check at Department of Social Security (DSS)

\begin{tabular}{|c|c|c|c|c|c|c|}
\hline \multirow{3}{*}{$\begin{array}{l}\text { Final } \\
\text { outcome of } \\
\text { DSS check } \\
\\
\\
\begin{array}{l}\text { Alive on } \\
\text { 1 Jan '84 }\end{array}\end{array}$} & \multicolumn{6}{|c|}{ Outcome of attempt at follow up, excluding information from DSS } \\
\hline & \multirow{2}{*}{$\begin{array}{l}\text { Evidence of } \\
\text { death by } \\
1 \text { gan } 1984 \\
\text { but no cause } \\
\text { of death } \\
\text { available }\end{array}$} & $\begin{array}{l}\text { Traced on } \\
\text { NHSCRs and not } \\
\text { registered } \\
\text { with a general } \\
\text { practitioner }\end{array}$ & $\begin{array}{l}\text { Untraced } \\
\text { on NHSCRs } \\
\text { and no } \\
\text { indication } \\
\text { of residence in } \\
\text { N Ireland, } \\
\text { Isle of Man } \\
\text { or fersey }\end{array}$ & $\begin{array}{l}\text { Untraced } \\
\text { in N Ireland, } \\
\text { Isle of Man } \\
\text { or fersey }\end{array}$ & \multicolumn{2}{|l|}{ Total } \\
\hline & & $2290(86 \cdot 7)$ & $381 \quad(65.5)$ & $94 \quad(81 \cdot 0)$ & 2779 & $(80 \cdot 3)$ \\
\hline $\begin{array}{l}\text { Dead by } \\
1 \text { Jan ' } 84\end{array}$ & $101 \quad(82 \cdot 1)$ & $83(3 \cdot 1)$ & $76 \quad(13 \cdot 1)$ & $14(12 \cdot 1)$ & 274 & $(7 \cdot 9)$ \\
\hline $\begin{array}{l}\text { Emigrated by } \\
1 \text { Jan } 84\end{array}$ & $3(2 \cdot 4)$ & $250 \quad(9 \cdot 5)$ & $113(19 \cdot 4)$ & $8 \quad(6.9)$ & 374 & $(10 \cdot 8)$ \\
\hline Untraced & $5(4 \cdot 1)$ & $19 \quad(0 \cdot 7)$ & $11(1.9)$ & $0 \quad(0.0)$ & 35 & $(1 \cdot 0)$ \\
\hline Total & $123(100)$ & $2642^{\mathrm{C}} \quad(100)$ & $581(100)$ & $116(100)$ & $3462^{\mathrm{c}}$ & $(100)$ \\
\hline
\end{tabular}


information available from DSS; six were reported by DSS to have died in England and Wales, one in Scotland, and four abroad. Of the remaining men traced on the NHS Central Registers but not registered with a general practitioner, $250(9.5 \%)$ were reported by DSS to have emigrated, for 137 of whom the final address recorded by the Ministry of Defence after discharge was outside the United Kingdom. Finally $19(0.7 \%)$ men listed as not currently registered in the NHS Central Registers could not be traced by DSS.

Of the 581 men who were untraced on the NHS Central Registers with no indication of residence in Northern Ireland, Isle of Man or Jersey, 379 were reported by DSS as alive and living in the United Kingdom according to their records and two more were reclassified as alive by DSS after the report of death could not be confirmed by OPCS, making a total of $381(65.5 \%)$. However for 159 of these there was some indication that the man had emigrated, in that the final address after discharge held by the Ministry of Defence was outside the United Kingdom. For a further 76 $(13.1 \%)$ untraced on the NHS Central Registers, DSS reported that the man had died. For 59 of these 76 , the extra information supplied by DSS enabled a death certificate to be obtained. Forty one of the men had died in England or Wales, 12 in Scotland, four in Northern Ireland, and two in Eire. For the remaining 17 of the 76, OPCS could confirm the date of death but could not supply a death certificate for six (five were reported in Scotland and one probably abroad), and could not confirm the date of death for 11 (three reported in England or Wales, one in Scotland, one in Northern Ireland, one abroad, four possibly abroad, and one place unknown). One hundred and thirteen $(19.4 \%)$ of the 581 men untraced on the NHS Central Registers were reported by DSS to have emigrated and for all but 11 of these the final address available from the Ministry of Defence was also outside the United Kingdom. Finally $11(1.9 \%)$ of the men untraced on the NHS Central Registers could not be traced by DSS; six of these were both born outside the United Kingdom and, according to the information from the Ministry of Defence, lived outside the United Kingdom after their discharge from service, so that they may never have lived as civilians in the United Kingdom or been registered with the National Health Service.

Of the 116 men untraced with the Health Departments in Northern Ireland, the Isle of Man or Jersey, $94(81.0 \%$ ) were reported by DSS as alive and living in the United Kingdom according to their records. DSS reported that a further 14 men $(12.1 \%)$ had died, all of whom were born in Northern Ireland, and for 11 of these the extra information enabled a death certificate to be found. Seven of the deaths were in Northern Ireland, three in England and Wales, and one in Scotland. Two men were reported by DSS to have died in England or Wales and OPCS could confirm the date of death but could not supply a death certificate, and one man was reported by DSS to have died in Northern Ireland, but the Health Department could not confirm the death. Finally, for eight of those untraced in Northern Ireland, the Isle of Man or Jersey, DSS reported that the man had emigrated, and for six of the eight an address outside the United Kingdom after discharge was given on the Ministry of Defence Record of Service.

For the men for whom follow up using the NHS Central Registers and Health Departments was apparently satisfactory, the outcome of the cross check with DSS is shown in table III. Of the 894 men born before 1 January 1916 and reported by the NHS Central Registers as currently registered with a general practitioner, DSS reported that 857 were alive and living in the UK on 1 January 1984 and six were reclassified by DSS as alive after a report of death could not be confirmed by OPCS, making a total of $863\left(96.5^{\circ}\right)$. Eleven men $\left(1 \cdot 2^{\circ}{ }_{0}\right)$ were found to have died. The additional information supplied by DSS enabled death certificates to be obtained for 10 of these men (six in England or Wales, two in Scotland, one in Northern Ireland, and one abroad) while the last man was reported to have emigrated prior to death. For $10\left(1.1^{\circ}{ }_{0}\right)$ of the men born before 1 January 1916 and reported by the NHS Central Registers as currently registered with a general practitioner, DSS reported that the man had emigrated, and three of these had final addresses after discharge from the Ministry of Defence that were outside the United Kingdom. The last 10 men were untraced.

Table III also shows the outcome of the cross check of the $1 \%$ sample of men born on or after 1 January 1916 and for whom follow up using the NHS Central Registers and Health Departments was apparently satisfactory. For 391 of the 413 $(94.7 \%)$, the outcome of the cross check at DSS confirmed the result of the initial follow up; 369 as alive (including two traced in Northern Ireland, Isle of Man or Jersey), 17 as dead, and five as
Table III Numbers of men in groups for whom follow up achieved using National Health Service Central Registers (NHSCRs) and Health Departments in $N$ Ireland, Isle of Man and Ireland, Isle of Man and satisfactory by outcome of cross check at Department of Social Security (DSS

\begin{tabular}{|c|c|c|c|c|c|c|}
\hline \multirow{2}{*}{$\begin{array}{l}\text { Final } \\
\text { outcome of } \\
\text { DSS check }\end{array}$} & \multirow[b]{2}{*}{$\begin{array}{l}\text { Men born before } \\
1 \text { fan } 1916 \text { and } \\
\text { reported by } \\
\text { NHSCR as } \\
\text { currently } \\
\text { registered } \\
\text { with a } \\
\text { general } \\
\text { practitioner }\end{array}$} & \multicolumn{5}{|c|}{$1^{\circ}{ }_{o}$ sample of men born on or after 1 fan 1916} \\
\hline & & $\begin{array}{l}\text { Registered } \\
\text { with a } \\
\text { general } \\
\text { practitioner }\end{array}$ & Emigrated & $\begin{array}{l}\text { Deceased by } \\
1 \text { fan } 1984 \\
\text { and cause } \\
\text { of death } \\
\text { available }\end{array}$ & $\begin{array}{l}\text { Traced in } \\
\text { N Ireland, } \\
\text { Isle of Man } \\
\text { or fersey }\end{array}$ & $\begin{array}{l}\text { Total 1" } \\
\text { sample }\end{array}$ \\
\hline $\begin{array}{l}\text { Alive on } \\
1 \text { Jan ' } 84\end{array}$ & $863(96 \cdot 5)^{a}$ & $367 \quad(98 \cdot 4)$ & $16(76 \cdot 2)$ & 0 & 2 & $385 \quad(93 \cdot 2)$ \\
\hline $\begin{array}{l}\text { Dead by } \\
1 \text { Jan ' } 84\end{array}$ & $11^{\mathrm{b}} \quad(1 \cdot 2)$ & $0 \quad(0.0)$ & $0 \quad(0.0)$ & 17 & 0 & $17 \quad(4 \cdot 1)$ \\
\hline $\begin{array}{l}\text { Emigrated by } \\
1 \text { Jan ' } 84\end{array}$ & $10 \quad(1 \cdot 1)$ & $4 \quad(1 \cdot 1)$ & $5(23 \cdot 8)$ & 0 & 0 & $9 \quad(2 \cdot 2)$ \\
\hline Untraced & $10 \quad(1 \cdot 1)$ & $2 \quad(0.5)$ & $0 \quad(0 \cdot 0)$ & 0 & 0 & $2 \quad(0 \cdot 5)$ \\
\hline Total & $894(100)$ & $373(100)$ & $21(100)$ & 17 & 2 & $413(100)$ \\
\hline
\end{tabular}

${ }^{a}$ Percentages in parentheses

$b$ Including one after emigration 
emigrated, and no further deaths were reported by DSS in this group. For four men reported by the NHS Central Registers as registered with a general practitioner, DSS reported that the man had emigrated, and for 16 men reported by the NHS Central Registers to have emigrated, DSS did not report an emigration. In these two groups, four and five of the men respectively also had final addresses with the Ministry of Defence that were outside the United Kingdom. No additional deaths were discovered, but two men could not be traced.

\section{Discussion}

In recent years several large cohort studies have supplemented mortality information obtained from the NHS Central Registers with information from DSS. ${ }^{5}{ }^{6}$ However the value of this additional procedure has not been documented. In the present study the submission to DSS of the details of the 3462 men in the four categories for which the outcome of initial follow up using the NHS Central Registers and the Health Departments in Northern Ireland, Isle of Man, and Jersey was unsatisfactory resulted in full death details, including cause of death, being made available for 178 men, of whom 142 were not previously thought to have died (see table IV). This represents an increase of $6 \cdot 5^{\circ}$ on the numbers of deaths with certified cause that would have been available without the information from DSS. Among those who had left the services and who were initially traced on the NHS Central Registers and found to be not currently registered with a general practitioner, full death details were eventually obtained for $2.7^{\circ}$ ( 72 out of 2642 ), while for those untraced on the NHS Central Registers or in Northern Ireland, the Isle of Man and Jersey, the figures were much higher, at $10 \cdot 2^{\circ}{ }_{o}$ (59 out of 581) and $9 \cdot 5^{\circ}{ }_{0}$ (11 out of 116) respectively (table IV). The vast majority of these men had died in the United Kingdom long after they had left the Services and, from the information available to us, no special feature could be identified that should have made either the men or their deaths difficult to find via the NHS Central Registers. In addition to those deaths for which full information was eventually obtained, the DSS also provided independent confirmation of death in 65 further men for whom some information that the man had died was already available, but for whom no cause of death could be found. A substantial proportion of these men died while in the Services or abroad.

In addition to the extra death information obtained as a result of the DSS check, a substantial number of extra emigrations were identified among those for whom follow up via the NHS Central Registers and Health Departments was unsatisfactory, and more would presumably have been found if DSS had been able to complete their searches. Overall $10 \cdot 8^{\circ}$ of men in these groups were reported by DSS to have emigrated (table II), but among those untraced on NHS Central Registers and with no indication of residence in Northern Ireland, Isle of Man or Jersey the figure was much higher, at $19 \cdot 4^{\circ}{ }_{0}$.

Among those for whom the follow up achieved using NHS Central Registers and Health Departments was apparently satisfactory, the DSS information enabled full death details to be obtained for 10 men $\left(1 \cdot 1^{\circ}{ }_{0}\right)$ born before 1 January 1916, and an extra 11 emigrations were noted (included one of a man reported to have died) (table III). Among those born on or after 1 January 1916 , four $\left(1 \cdot 1^{\circ}{ }_{0}\right)$ extra emigrations were noted and no evidence of any additional deaths was found.

Every cohort study will necessarily have its own special features that influence the quality of the follow up achieved. In the present case the cohort was limited to men and the information for tracing was derived from Service records and was of exceptionally high quality, including both National Health Service and National Insurance numbers for a large proportion of men. Another special feature of the study was the fact that all members of the cohort had been members of the Armed Forces and had served abroad in tropical areas. In principle, each man's registration with his NHS general practitioner should have been cancelled on his enlistment, and he should have reregistered again after his discharge, but clearly this did not always happen, and the proportion of men traced on the NHS Central Registers and found to be not currently registered with a general practitioner may well have been unusually high.
Table IV Numbers of men for whom follow up achieved using National Health Service Central Registers (NHSCRs) and Health Departments was unsatisfactory and whom DSS reported as dead by 1 fanuary 1984 by outcome of attempt at follow up, excluding and follow up, excluding and Department of Social Security (DSS)

\begin{tabular}{|c|c|c|c|c|c|}
\hline \multirow{2}{*}{$\begin{array}{l}\text { Final outcome of } \\
\text { follow up using } \\
\text { DSS information }\end{array}$} & \multicolumn{5}{|c|}{ Outcome of attempt at follow up, excluding information from DSS } \\
\hline & $\begin{array}{l}\text { Evidence of } \\
\text { death by } \\
1 \text { fan } 1984 \\
\text { but no cause } \\
\text { of death } \\
\text { available }\end{array}$ & $\begin{array}{l}\text { Traced on } \\
\text { NHSCRs and } \\
\text { registered } \\
\text { with a general } \\
\text { practitioner }\end{array}$ & $\begin{array}{l}\text { Untraced } \\
\text { on NHSCRs } \\
\text { and no } \\
\text { indication } \\
\text { of residence in } \\
N \text { Ireland, } \\
\text { Isle of Man } \\
\text { or fersey }\end{array}$ & $\begin{array}{l}\text { Untraced } \\
\text { in N Ireland, } \\
\text { Isle of Man } \\
\text { or fersey }\end{array}$ & Total \\
\hline $\begin{array}{l}\text { Dead by } 1 \text { January } \\
1984 \text { and certified } \\
\text { cause of death available }\end{array}$ & $36^{\mathrm{a}}$ & 72 & 59 & 11 & 178 \\
\hline $\begin{array}{l}\text { Confirmation of } \\
\text { death notified by } \\
\text { OPCS or MOD, but no } \\
\text { certified cause available }\end{array}$ & $65^{\mathrm{b}}$ & 0 & 6 & 2 & 73 \\
\hline $\begin{array}{l}\text { No confirmation } \\
\text { of death from } \\
\text { source outside DSS }\end{array}$ & 0 & 11 & 11 & 1 & 23 \\
\hline $\begin{array}{l}\text { Total reported } \\
\text { by DSS as dead } \\
\text { by } 1 \mathrm{Jan} 1984\end{array}$ & 101 & 83 & 76 & 14 & 274 \\
\hline
\end{tabular}


The age distribution of the men, the period of investigation, and the fact of service abroad may well have resulted in an unusually high proportion of emigrations. Finally, the period of follow up in the present study extended only to the beginning of 1984, 15 months before the abolition of the death grant. Thus for studies with follow up period extending beyond March 1985 the information that DSS can supply may not be of quite such good quality as that obtained here.

Despite the special features of the cohort under study three general conclusions can be drawn. The first of these is that it is inappropriate to assume, as is often done, that those men who are traced on the NHS Central Registers and not currently registered with a general practitioner are alive and living in the United Kingdom. In the present study at least $2.7 \%$ of such men had died and at least a further $9.5 \%$ had emigrated, so their deaths would not necessarily be recorded either on the NHS Central Registers or by DSS. If it is not possible to carry out any special additional follow up of men who are not currently registered it might be better to assume that the men were lost to follow up when, or perhaps shortly before, their last registration was cancelled.

Secondly, the mortality among those untraced on the NHS Central Registers or with another Health Department is likely to be exceptionally high. In this study at least $10 \%$ of such men had died (table II), compared with about $7 \%$ of men who were satisfactorily traced. ${ }^{2}{ }^{3}$ Emigration in this group was also considerably higher than that overall. It thus seems highly desirable to take every possible step to ensure that the numbers untraced are kept as small as possible, and to use every available additional method of follow up for those that remain.
Finally, there is evidence that a few deaths and some emigrations are missed by the NHS Central Registers among those apparently traced as currently registered with a general practitioner, especially among those aged over about 70 years. Thus in any study, even when allowance is made for those not satisfactorily traced, the estimated standardised mortality ratios based on follow up via the NHS Central Registers are likely to be somewhat too low, and this should be borne in mind when interpreting the data.

The study on which this paper is based was commissioned by and carried out for the Ministry of Defence. We are most grateful to the staffs of the National Health Service Central Registers and the Records Branch of the Department of Social Security for their work in providing follow up information, and to Dr A J Fox for helpful comments on an earlier draft. We also thank Sandra Connell-Hinkes and Sarah Jones for typing the manuscript.

1 Office of Population Censuses and Surveys. The National Health Service Central Register as an aid to medical research. A guide for potential applicants. London: OPCS, 1982.

2 Darby SC, Kendall GM, Fell TP, et al. A summary of mortality and incidence of cancer in men from the United Kingdom who participated in the United Kingdom's Kingdom who participated in the United Kingdom's atmospheric nuclear weapon tests and
programmes. $\mathrm{Br}$ Med $\mathcal{f} 1988 ; 296: 332-8$.

3 Darby SC, Kendall GM, Fell TP, et al. Mortality and cancer incidence in UK participants in UK atmospheric nuclear weapon tests and experimental programmes. NRPB Report R214. London: HMSO, 1988

4 Beral V, Fraser P, Carpenter L, Booth M, Brown A, Rose E. Mortality of employees of the Atomic Weapons Establishment, 1951-82. Br Med f 1988; 297: 757-70.

5 Fraser P, Booth M, Beral V, Inskip H, Firsht S, Speak S. Collection and validation of data in the United Kingdom Atomic Energy Authority mortality study. Br Med $\mathcal{F} 1985$; 291: 435-9.

6 Smith PG, Douglas A. Mortality of workers at the Sellafield plant of British Nuclear Fuels. Br Med F 1986; 293: 845-54. 